\title{
Frequency of IL-10+CD19+ B cells in patients with prostate cancer compared to patients with benign prostatic hyperplasia
}

\author{
Nazmabadi Roya ${ }^{1}$, Taheri Fatemeh², Mohammad-Alibeigi Faramarz ${ }^{3}$, Sabzevary-Ghahfarokhi Milad ${ }^{1}$, \\ Sanaei Mohammad-Javad ${ }^{1}$, Salehi-Vanani Najmeh ${ }^{4}$, Mirzaei Yousef ${ }^{5}$, Bagheri Nader ${ }^{1}$
}

1. Cellular and Molecular Research Center, Basic Health Sciences Institute, Shahrekord University of Medical Sciences, Shahrekord, Iran

2. Department of Pathology, Shahrekord University of Medical Sciences, Shahrekord, Iran

3. Department of Urology, Shahrekord University of Medical Sciences, Shahrekord, Iran

4. Clinical Biochemistry Research Center, Basic Health Sciences Institute, Shahrekord University of Medical Sciences, Shahrekord, Iran.

5. Scientific Research Center, Soran University, Soran, Kurdistan Region, Iraq.

\begin{abstract}
Background: The function of the immune system in prostate cancer (PC) might promote carcinogenesis. PC is a common cancer in men. Regulatory B cells (Bregs) are a new subtype of B cells that have suppressive roles in the immune system. Interleukin-10 (IL-10) is a dominant mediator of immune suppression released by Bregs.

Objective: The purpose of this research was to examine the frequency of CD19+IL10+ B cells and IL-10 mRNA expression in patients with PC compared to patients with benign prostatic hyperplasia (BPH).

Methods: Forty paraffin tissue samples from patients with PC and 32 paraffin tissue samples from patients with BPH were entered in this study. The immunohistochemistry staining was used to evaluate the pattern expression of CD19 and IL-10 markers. IL-10 mRNA expression in fresh tissue was determined by real time-polymerase chain reaction (RT-PCR).

Results: The frequency of CD19+IL-10+ B cells and IL-10 mRNA expression in PC patients were significantly higher than patients with BPH. Also, there was no meaningful relationship between the frequency of IL-10+CD19+ B cells and gleason scores in patients with PC.

Conclusions: Our findings suggested that frequency of IL-10+CD19+ B cells correlates with progressive stage of PC.

Keywords: Prostate cancer; benign prostatic hyperplasia; IL-10+CD19+ B cells.

DOI: https://dx.doi.org/10.4314/ahs.v20i3.31

Cite as: Roya N, Fatemeh T, Faramarz M-A, Milad S-G, Mohammad-Javad S, Najmeh S-V, et al. Frequency of IL-10+CD19+ $B$ cells in patients with prostate cancer compared to patients with benign prostatic byperplasia. Afri Health Sci. 2020;20(3): 1264-1272. https:// dx.doi.org/10.4314/ahs.v20i3.31
\end{abstract}

\section{Introduction}

Prostate cancer (PC) is the second most prevalent type of male cancer-related death all over the world. In the tu-

\section{Corresponding author:}

Bagheri Nader,

Cellular and Molecular Research

Center, Basic Health Sciences Institute,

Shahrekord University of Medical Sciences,

Shahrekord, Iran.

Tel.: +98 9181731073;

Fax: +98-3813330709.

E-mail addresses: n.bagheri1985@gmail.com mor microenvironment (TME), the complex cellular interaction of immune cells is involved in progression of ${ }^{1,2}$. Recently, multiple diagnostic approaches including typical cancer staging (TNM), histological characteristics of a prostate biopsy and prostate specific antigen (PSA) levels are considered to distinguish $\mathrm{PC}^{3}$. The immune system can promote cancer development ${ }^{4}$. Likewise, specific immune cells exclusively release mediators in TME, leading to immune system suppression ${ }^{5-7}$. There may be prognostic markers in identifying tumor promoting immune cells in patients with $\mathrm{PCa}^{4}$. Recently, the performance of regulatory B cells (Bregs) in immunosuppression has raised researchers' attention as a key novel cell in cancer development. In regard to the function, Bregs are highly sim- 
ilar to T regulatory cells (Tregs) and myeloid suppressive cells (MSC) ${ }^{8-10}$. Katz et al in 1974 recognized a different $\mathrm{B}$ cell subset, which delayed hypersensitivity on adoptive transfer ${ }^{11}$. Bregs decrease has been shown to exacerbate the signs of disease in autoimmune diseases ${ }^{12}$, chronic inflammatory diseases ${ }^{13}$, chronic inflammatory disease, or increase tumor growth ${ }^{14}$. CD19+CD24hiCD38hi ${ }^{15}$ and CD19+IL-10+16 were extensively considered as markers for Bregs in human. Bregs can arrest the T-cell-mediated inflammatory response mainly via secreting IL-10. In regulating human $\mathrm{CGVHD}$, the secretion of IL-10 in $\mathrm{B}$ cells within the CD24hiCD27+ and CD27 high CD38 high markers is essential ${ }^{16}$. IL-10-producing $\mathrm{B}$ cells can transform effector T cells to IL-10-producing suppressive $\mathrm{T}$ cells for a longer period of time through interaction with CD4+CD25- T cells ${ }^{17,18}$. It has been shown that CD19-/- significantly enhances the function of T-cells ${ }^{19}$. The high presence of CD5+CD19+IL-10+ Bregs in patients' peripheral blood indicated that Bregs play an important role in carcinogenesis growth and prognosis $^{20}$.

This research aimed at investigating the frequency of CD19+IL10+ B cells and IL-10 mRNA expression in PC patients compared to patients with benign prostatic hyperplasia $(\mathrm{BPH})$ and their correlation with Gleason score.

\section{Material and methods \\ Study population}

The present study included all 72 patients diagnosed with biopsy obtained during prostatectomy at the Kashani hospital in Shahrekord. Before the study, none of the patients received radiotherapy, radiation or other medical interventions. Patients with concurrent malignancies, autoimmune diseases or immune defects were excluded from the study. The control group was selected from the benign prostatic hyperplasia $(\mathrm{BPH})$ from the patients who were undergone open prostatectomy for PC screening. The mean age was 65.63 \pm 14.42 . Data on age is expressed mean \pm SD and other data are reported as percentages.

\section{Patients and tissue samples}

The suitable Institutional Ethic Committees of the Shahrekord University of Medical Sciences approved the use of human samples for this study. All patients gave written informed consent. Forty two patients with PC underwent radical prostatectomy and 32 patients with $\mathrm{BPH}$ underwent open prostatectomy. Besides, 20 fresh tissue samples of both PC and BPH were obtained for RNA extraction. Clinical information such as age, grade and stage were collected from medical files, and the names of participants remained confidential. The initial diagnosis of the probability of prostate cancer was checked using radiology photos, serum levels of prostate-specific antigen (PSA), and digital rectum exam (DRE) by a urologist. Then after obtaining samples by prostatectomy, the samples were transferred to the pathology lab and a definitive diagnosis was made about the health or malignancy of the tissues. Also, in case of malignancy, low grade and high grade samples were detected and reported by pathologist. The histological grade and stage of PC was classified based on the Gleason system (GS Intermediate: $<7$; GS Progressive: $>7)^{21,22}$. GS is a grading system that is determined by adding the most and second most common patterns ranging from 2 to $10^{22}$.

\section{Immunohistochemistry staining}

Radical prostatectomy samples were cut and parts of PC specimens were first embedded in 10\% formalin buffered and then embedded in paraffin. The paraffin blocks were cut into $4 \mu \mathrm{m}$ thick pieces with microtomes. For immunohistochemical staining, 4- $\mu \mathrm{m}$ serial sections were made and spread on poly-L-lysine- coated slides. Paraffin parts were dried and warmed in a $68^{\circ} \mathrm{C}$ oven overnight. The parts were then deparaffinized using three xylene modifications and rehydrated using a sequence of alcohols $(100 \%, 100 \%, 80 \%$ and $70 \%)$. For antigen retrieval the parts were inundated in citrate buffer $(10 \mathrm{mM}$ Sodium Citrate, $0.05 \%$ Tween $20, \mathrm{pH} 6.0$ ) and subjected to autoclaving pressure and heat for 20 minutes to reveal concealed antigens for improved adhesion to antibodies in the next stages. In the next step protein blocks were added to the sections (ab94665, Abcam, UK) in order to block and hinder nonspecific background staining and were incubated for 2 hours. After washing the parts with distilled water, Anti-human CD19 mouse antibody (ab31947, ebioscience, UK) at a 1:200 dilution, anti-human IL-10 Rabbit antibody (ab34843, Abcam, UK) at a 1:400 dilution was applied. Afterwards, the parts were then put overnight in a suitable moisture chamber at $4{ }^{\circ} \mathrm{C}$. The next day, after rinsing the slides in TBST buffer, $3 \% \mathrm{H}_{2} \mathrm{O}_{2}$ in TBS for 15 min was applied to parts for preventing endogenous peroxidase activity. Later, Biotinylated goat anti-rabbit and mouse IgG (ab93697, Abcam, UK) which is also called secondary antibody was added and the sections were in- 
cubated for 1 hour at room temperature in moist chamber. After the incubation time, the sections were incubated with Streptavidin Peroxidase Plus at room temperature for 10 minutes. Next, the chromogenic segment called 3-diaminobenzidine tetrahydrochloride (DAB) was incubated for 10 minutes (ab94665, Abcam, UK). After washing with the TBST buffer, parts were placed with Meyer's hematoxyline for 1 minute and washed with cold water and mounted. Human tonsil tissue was used as positive control for CD19 and IL-10. Sections without any primary antibody were considered as negative control. The numbers of CD19 and IL-10 cells were determined in 10 high-power fields by calculating positive cells in the entire tissue area. Outcomes were expressed as the mean value of all tested patients in any group.

\section{RNA extraction and Real-time PCR (RT-PCR)}

Twenty fresh tissue biopsies containing 10 PC and 10 $\mathrm{BPH}$ samples were taken from radical prostatectomy and open prostatectomy. Before analysis, specimens were held at $-70^{\circ} \mathrm{C}$. TRIzol ${ }^{\circledR}$ Plus RNA reagent extracted the total RNA. The concentration of each RNA sample was calculated by Thermo Scientific TM NanoDrop 2000. Complementary DNAs (cDNA) were produced with reverse transcriptase (RT) using the First Strand cDNA Synthesis Kit (Fermentas Life Sciences, cat- K1622) with $2.5 \mu \mathrm{g}$ RNA at a $20 \mu \mathrm{L}$ reaction volume. The amplification of IL-10 cDNA in a Rotorgene 3000 (Corbett Life Science) was performed using the SYBR Green RT-PCR method. The primer sequences of IL-10 applicated in the RT-PCR include: IL-10 5'TCAAGGCGCATGTGAACTC-3 (Forward), 5`CGGCCTTGCTCT'TGT'T'T'TC-3` (Reverse) and GAPDH 5 'TTCACCACCATGGAGAAGGC-3` (Forward), 5`-CCCTTT'TGGCTCCACCCT-3` (Reverse) as internal control (housekeeping genes) was used. Also, each sample was accomplished in duplicate. RT-PCR reactions were performed in a total volume of $20 \mu \mathrm{l}$ containing of $1 \mu \mathrm{L}$ diluted cDNA, $1 \mu \mathrm{L}$ of each oligonucleotide primers, $7 \mu \mathrm{L}$ nuclease free $\mathrm{H} 2 \mathrm{O}$ and $10 \mu \mathrm{L}$
2X SYBR Green Master Mix. Negative control samples were constructed by deleting the diluted cDNA from the reaction mixture. RT-PCR was started with a 5-minute denaturation stage at $95^{\circ} \mathrm{C}$ and next in 35 amplification cycles that each cycle was included of $95^{\circ} \mathrm{C}$ denaturation at $10 \mathrm{~s}, 60^{\circ} \mathrm{C}$ annealing at $20 \mathrm{~s}$, and $72^{\circ} \mathrm{C}$ extension at $30 \mathrm{~s}$. At the melting step, which is the last stage quality of examination was determined.

\section{Statistical analysis}

Analysis was carried out in duplicate and all data were shown as mean $\pm \mathrm{SD}$. The usual data distribution was validated by the normality check of Shapiro-Wilk. T test (To compare the two samples) or Tukey post hoc test (for multiple comparisons) evaluated quantitative data, comparing diseased groups with a different GraphPad Prism software version 8 control group (GraphPad Software, La Jolla, CA, USA). Pearson's parametric information association analysis was used to determine the relationship between variables. The relationship between gene expression levels and PC existence was evaluated using a multivariate logistic regression model. Where the P-value was less than 0.05 , statistical significance was considered.

\section{Results}

\section{Increased expression of IL-10 in PC (tumor tissues) compared with BPH}

In our analysis, real-time PCR of 20 PC samples and 20 BPH samples assessed the mRNA expression of IL-10. The IL-10 mRNA was significantly higher in PC patients compared with BPH group (Fig. 1A; P < 0.0001). ). If the mean of IL-10 expression in tumor tissue is 4.80 and the mean of IL-10 expression in non-tumoral tissue is 1.35 then the difference in the IL-10 expression in tumor tissue compared with non-tumoral tissue is 3.55-fold (4.08/1.35). The IL-10 gene expression in both intermediate and progressive groups of PC was more than that in the $\mathrm{BPH}$ group; however, there was no significant difference between intermediate and progressive groups (Fig. 1). 


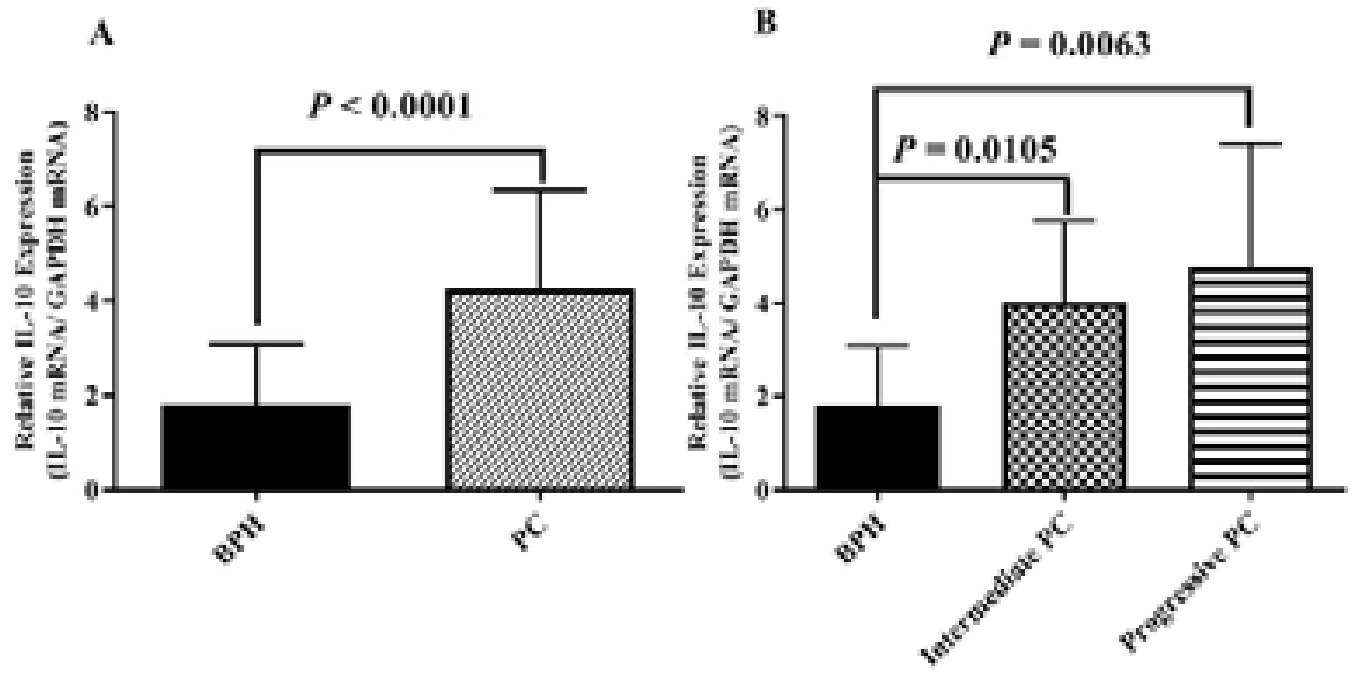

Figure 1. IL-10 mRNA level was evaluated in radical prostatectomy specimens. A) IL-10 gene expression in 20 PC samples and $20 \mathrm{BPH}$ samples was shown. The real-time PCR results were standardized for human IL-10 versus GAPDH. B) In prostatectomy samples, the gene IL-10 was significantly over-expressed in intermediate and progressive PC patients rather than BPH. P-values less than 0.05 is statistically significant. PC: Prostate Cancer; BPH: benign prostatic hyperplasia.

The frequency of CD19+IL-10+ $B$ cells was increased in prostatectomy tissue of PC

The prostatectomy tissues were immunostained with anti-CD19 and anti-IL-10 antibodies to detect Breg cells in samples (Fig.2). We observed that there is a significant increase in the frequency of CD19+IL-10+ B cells PC tissues than BPH tissues (Fig.3A; P =0.0014). Also, the number of CD19+IL-10+ B cells in intermediate and progressive groups of $\mathrm{PC}$ was higher than the $\mathrm{BPH}$ group (Fig.3B; P $=0.0258$ and 0.0225 , respectively). The presence of PCs was positively correlated with the high frequency of IL-10 and CD19+IL-10+ B cells in multivariable logistic regression analysis. $(\mathrm{P}=0.033,0.014)$ (Table 2). Per 1 unite rise in frequency of CD19+IL-10+ $\mathrm{B}$ cells, the possibility of PC development was 1.34 times higher than the control group.
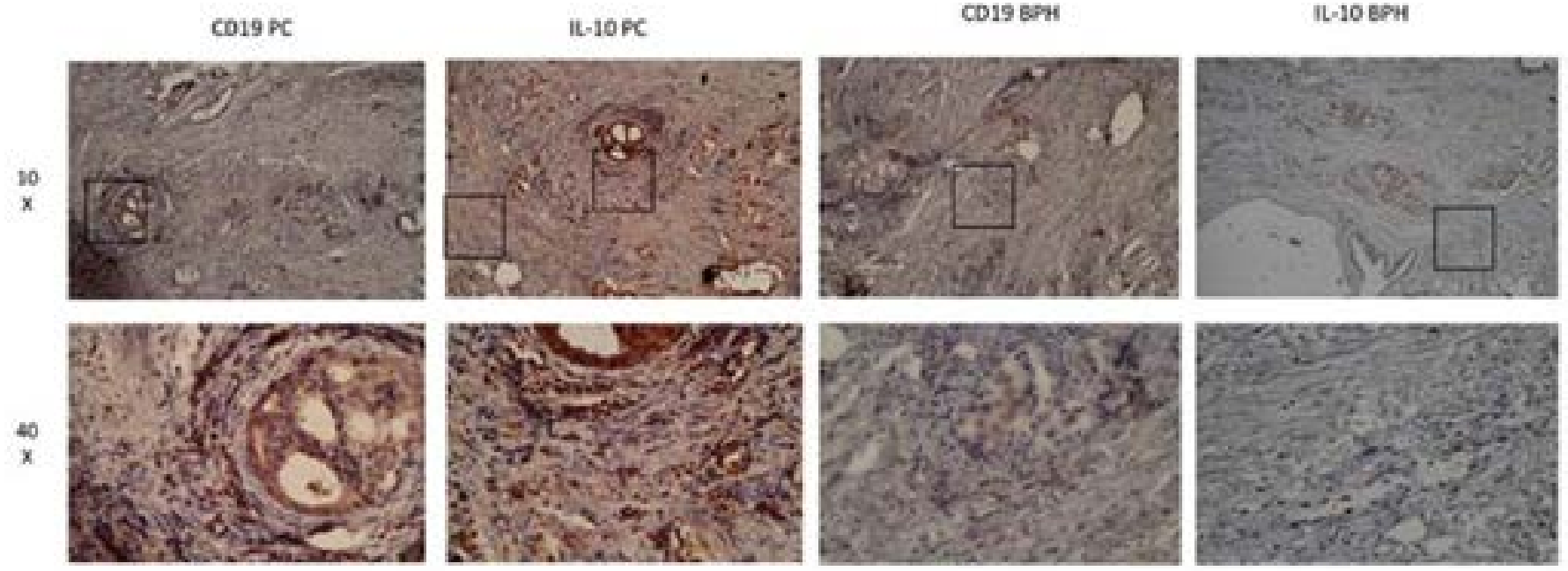

Figure 2. Assessment of prostatectomy tissues in immunohistochemistry for CD19 and IL-10 markers. Formalin-fixed and paraffin-embedded were stained with anti-CD19 and anti-IL-10 antibodies. Sequence sections of tissue were used to immunostaining CD19 and IL-10. CD19+IL-10+ B cells dominantly appear in the PC tissues. 


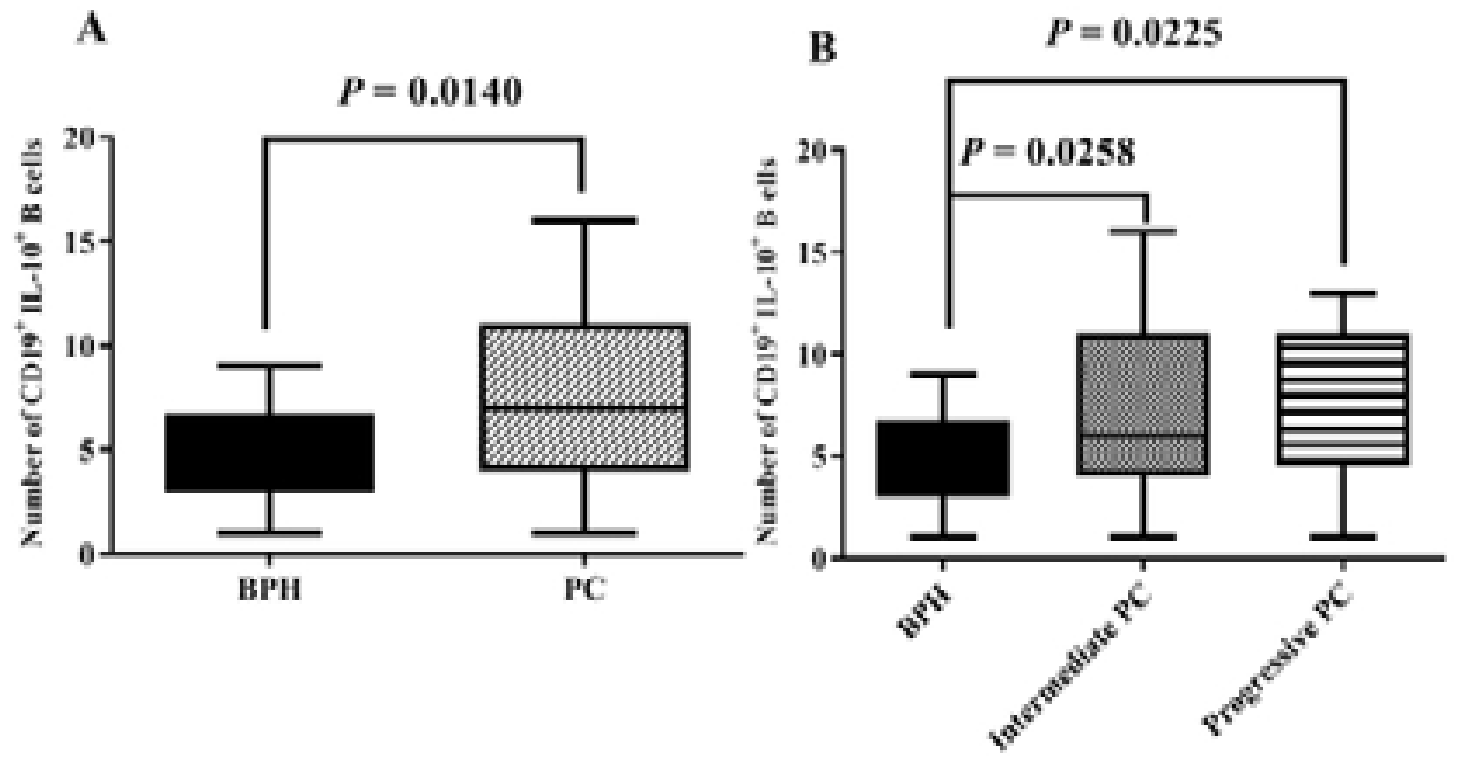

Figure 3. The frequency of CD19+IL-10+ B cells is shown. The number of CD19+IL-10+ B cells in the PC group was 1.5 higher than BPH group. P-values less than 0.05 is statistically significant. PC: Prostate Cancer; BPH: benign prostatic hyperplasia.

Table 1. Clinical and pathological characteristics

\begin{tabular}{|l|l|}
\hline & All $(\mathrm{n}=72)$ \\
\hline FFPE samples PCa/BPH & $72-40 / 32$ \\
\hline Fresh samples PCa/BPH & $20-10 / 10$ \\
\hline Mean age \pm SD, years PCa/BPH & $77.38 / 73.61$ (p-value was not significant) \\
\hline$\leq 70$ y & $25 / 72$ \\
\hline$>70$ y & $47 / 72$ \\
\hline Pathologic Gleason score & \\
\hline$<7$ & $14 / 42$ \\
\hline$\geq 7$ & $28 / 42$ \\
\hline Median PSA ( ng/mL) & $16 / 72$ \\
\hline$<4 \mathrm{ng} / \mathrm{ml}$ & $29 / 72$ \\
\hline $\begin{array}{l}4-10 \mathrm{ng} / \mathrm{ml} \\
>4 \mathrm{ng} / \mathrm{ml}\end{array}$ & $27 / 72$ \\
\hline
\end{tabular}

PCa, prostate cancer; BPH, benign prostate hyperplasia; FFPE, Formalin-fixed paraffin embedded; PSA, prostate-specific antigen 
Table 2. Coefficients of the logistic regression analysis for the existence of PC.

\begin{tabular}{|c|c|c|c|c|c|}
\hline & $\begin{array}{c}\text { Regression } \\
\text { coefficient } \\
(\beta)\end{array}$ & Standard error & \multirow{2}{*}{$P$-value } & \multicolumn{2}{|c|}{$95 \%$ C.I for Eep (B) } \\
\cline { 4 - 6 } & 1.342922 & 0.1861459 & $0.033^{*}$ & 0.0231172 & 0.5665123 \\
\hline Breg cell & 1.586061 & 0.2976891 & $0.014^{*}$ & 0.0933858 & 0.8291207 \\
\hline Frequency of IL-10 & 1.086774 & 0.1608512 & 0.574 & -0.2068765 & 0.3733041 \\
\hline Frequency of & & & & & \\
\hline CD19 & & & & & \\
\hline
\end{tabular}

* The presence of PC was significantly correlated with high level of IL-10 and Breg

\section{Discussion}

PC is one of the most generally diagnosed cancers among men all over the world, and mortality has been on the rise 23. The effects of immunotherapeutic strategies are dependent on interaction of tumor cells and host immune response ${ }^{24}$. The lymphocytes that are infiltrated in tumor tissue have the potential to be used as the positive prognostic relation in cancer. An analysis of 50 high-grade PC transurethral prostate samples found that the rate of manually counted $\mathrm{CD} 20+\mathrm{B}$ cells in the PC was significantly higher than in the control group ${ }^{25}$. This investigation probably indicates that $\mathrm{B}$ cells may have an effective role in cancer development tumor genesis process. Another study showed that $\mathrm{B}$ cells can generate different cytokines such as lymphotoxin, which is able to activate signaling pathways in tumor cells of patients with castration-resistant prostate cancer (CRPC) ${ }^{26}$. Shimabukuro-Vornhagen et al. suggested that a decrease in the number of $B$ cells in colorectal cancer and an enhanced proportion of Bregs that contribute to metastasis may represent immune escape $^{27}$.

Several studies on various lymphoid malignancies in humans have shown that malignant B cells can act as Bregs that repress anti-tumor immune responses with their suppressive ligands ${ }^{28,29}$. Overall, these studies on B cells can indicate that these cells have regulatory properties and have a direct effect on cancer growth ${ }^{30}$. Our results demonstrated that the frequency of CD19+IL-10+ B cells and IL-10 gene expression in PC patients were significantlyhigher than the patients with benign prostatic. In addition, the exponential rate of logistical regression showed that CD19+IL-10+ B cells and IL-10 cytokine could play a role in maintaining prostate cancer. Our findings suggest that the PC environment plays an important role in the induction of CD19+IL-10+ B cells differentiation or infiltration, which is confirmed by breast cancer cell studies that these cells can provoke Bregs expression in mice spleens ${ }^{31}$. According to available data, IL-10+CD19+ B cells accumulate in tumor areas and peri-tumor environment ${ }^{32}$. An immunohistochemical study on radical prostatectomy indicated the high frequency of $\mathrm{B}$ cell in malignant tissue against benign tissue ${ }^{33}$. These findings suggest that $B$ lymphocytes are critical in response to antitumor immunity and can differentiation to Bregs. PC microenvironment is more likely to be immunosuppressive ${ }^{34}$. Low cytolytic activity of NK cells was detected in prostate tumor milieu ${ }^{35}$. The high secretion of transforming growth factor beta (TGF- $\beta$ ) by prostate tissue inhibits NK cells and lymphocytes function and migration ${ }^{36}$. Furthermore, the agglomeration of Tregs and Th17 lymphocytes down-regulates antitumor immunity in $\mathrm{PC}^{37,38}$. A research by Zhou et al. found that factors released by lung cancer and infiltrated immune cells can play a significant role in Breg cell growth and the extent of inflammation ${ }^{39}$. Our results presumably have 
demonstrated that the expression of IL-10 has a relationship with the poor prognosis of cancer. IL-10 is an important mediator of immune suppression by Bregs ${ }^{40}$. A recent study of tongue squamous cell carcinoma (TSCC) found that IL-10+CD19+ B cells played an important role in transforming CD4+ T cells into Tregs via IL-10 secretion and worse prognosis in patients with TSCC 32. There are indications that Bregs can produce Tregs via cell contact and IL-10 secretion ${ }^{40}$. Also, the study showed that Bregs suppressor is IL-10, CD80, and CD86 dependent, but not TGF- $\beta$ in humans ${ }^{9}$, which was constant with our conclusions that IL-10 is critical cytokine in cancer. An analysis on the animal model of breast cancer, however, found that the conversion of CD4+ $T$ cells to Tregs was associated with increased TGF- $\beta$ levels rather than IL-10 ${ }^{31}$. Perhaps IL-10+CD19+ B cells through IL-10 are capable of suppressing immune cells in tumor microenvironment and promote metastasis through interactions with Tregs. Our findings suggested that an enhanced frequency of IL-10+CD19+ B cells may promote tumor progression in patients with PC through the secretion of anti-inflammatory mediators. Altogether, the use of CD19+IL-10+ B cells in cancer treatment may be much welcomed in the future, especially in the field of immune response to tumors.

\section{Acknowledgments}

This research was financially backed by Shahrekord University of Media Sciences research deputy with grant number 2723. The authors of this paper are thankful to the staff of Students Research Committee, Shahrekord University of Medical Sciences, Shahrekord, Iran and the staff of Cellular \& Molecular Research Center, Shahrekord University of Medical Sciences. The authors are also grateful to the authorities of the pathology unit of Shahrekord Kashani Hospital for their valuable cooperation.

\section{Ethical approval}

The ethical board of the University Of Medical Sciences Of Shahrekord authorized this research with the number: IR.Skums. REC.1397.63.

\section{Conflict of interest}

This manuscript was approved by all authors. No competing interests declared.

\section{References}

1. Sciarra A, Gentilucci A, Salciccia S, Pierella F, Del Bianco F, Gentile V, et al. Prognostic value of inflammation in prostate cancer progression and response to therapeutic: a critical review. J Inflamm (Lond). 2016;13:35.

2. Strasner A, Karin M. Immune Infiltration and Prostate Cancer. Front Oncol. 2015;5:128.

3. Heidenreich A, Bastian PJ, Bellmunt J, Bolla M, Joniau $\mathrm{S}$, van der Kwast T, et al. EAU guidelines on prostate cancer. part 1: screening, diagnosis, and local treatment with curative intent-update 2013. Eur Urol. 2014;65(1):124-37. 4. Shalapour S, Karin M. Immunity, inflammation, and cancer: an eternal fight between good and evil. The Journal of Clinical Investigation. 2015;125(9):3347-55.

5. Gabrilovich DI, Bronte V, Chen S-H, Colombo MP, Ochoa A, Ostrand-Rosenberg S, et al. The terminology issue for myeloid-derived suppressor cells. Cancer Research. 2007;67(1):425-.

6. Noguchi M, Koga N, Moriya F, Itoh K. Immunotherapy in prostate cancer: challenges and opportunities. Immunotherapy. 2016;8(1):69-77.

7. Topalian SL, Weiner GJ, Pardoll DM. Cancer immunotherapy comes of age. Journal of Clinical Oncology. 2011;29(36):4828.

8. Rosser EC, Blair PA, Mauri C. Cellular targets of regulatory B cell-mediated suppression. Mol Immunol. 2014;62(2):296-304.

9. Zhang Y, Eliav Y, Shin SU, Schreiber TH, Podack ER, Tadmor T, et al. B lymphocyte inhibition of anti-tumor response depends on expansion of Treg but is independent of B-cell IL-10 secretion. Cancer Immunol Immunother. 2013;62(1):87-99.

10. Olkhanud PB, Damdinsuren B, Bodogai M, Gress RE, Sen R, Wejksza K, et al. Tumor-evoked regulatory $\mathrm{B}$ cells promote breast cancer metastasis by converting resting CD4(+) T cells to T-regulatory cells. Cancer Res. 2011;71(10):3505-15.

11. Katz SI, Parker D, Turk JL. B-cell suppression of delayed hypersensitivity reactions. Nature. 1974;251(5475):550-1.

12. Watanabe R, Ishiura N, Nakashima H, Kuwano Y, Okochi H, Tamaki K, et al. Regulatory B cells (B10 cells) have a suppressive role in murine lupus: CD19 and B10 cell deficiency exacerbates systemic autoimmunity. The Journal of Immunology. 2010;184(9):4801-9.

13. DiLillo DJ, Matsushita T, Tedder TF. B10 cells and 
regulatory B cells balance immune responses during inflammation, autoimmunity, and cancer. Annals of the New York Academy of Sciences. 2010;1183(1):38-57.

14. Shao Y, Lo CM, Ling CC, Liu XB, Ng KT-P, Chu ACY, et al. Regulatory B cells accelerate hepatocellular carcinoma progression via CD40/CD154 signaling pathway. Cancer Letters. 2014;355(2):264-72.

15. Blair PA, Noreña LY, Flores-Borja F, Rawlings DJ, Isenberg DA, Ehrenstein MR, et al. CD19+ CD24hiCD38hi B cells exhibit regulatory capacity in healthy individuals but are functionally impaired in systemic lupus erythematosus patients. Immunity. 2010;32(1):129-40.

16. de Masson A, Bouaziz J-D, Le Buanec H, Robin M, O'Meara A, Parquet N, et al. CD24hiCD27+ and plasmablast-like regulatory $\mathrm{B}$ cells in human chronic graft-versushost disease. Blood. 2015;125(11):1830-9.

17. Liu F, Dai W, Li C, Lu X, Chen Y, Weng D, et al. Role of IL-10-producing regulatory B cells in modulating T-helper cell immune responses during silica-induced lung inflammation and fibrosis. Scientific Reports. 2016;6:28911. 18. Liu Z, Dang E, Li B, Qiao H, Jin L, Zhang J, et al. Dysfunction of CD19+ CD24 hi CD27+ B regulatory cells in patients with bullous pemphigoid. Scientific Reports. 2018;8(1):703.

19. Sarvaria A, Madrigal JA, Saudemont A. B cell regulation in cancer and anti-tumor immunity. Cellular \& Molecular Immunology. 2017;14(8):662.

20. Chen T, Song D, Min Z, Wang X, Gu Y, Wei B, et al. Perioperative dynamic alterations in peripheral regulatory $\mathrm{T}$ and $\mathrm{B}$ cells in patients with hepatocellular carcinoma. Journal of Translational Medicine. 2012;10(1):14.

21. Gleason DF. Classification of prostatic carcinomas. Cancer Chemother Rep. 1966;50:125-8 PubMed .

22. Epstein JI, Zelefsky MJ, Sjoberg DD, Nelson JB, Egevad L, Magi-Galluzzi C, et al. A contemporary prostate cancer grading system: a validated alternative to the Gleason score. European Urology. 2016;69(3):428 PubMed $-35$.

23. Kimura T, Egawa S. Epidemiology of prostate cancer in Asian countries. International Journal of Urology. 2018;25(6):524-31.

24. Brichard VG, Lejeune D. GSK's antigen-specific cancer immunotherapy programme: pilot results leading to Phase III clinical development. Vaccine. 2007;25:B61-B71. 25. Hussein M-RA, Mana A-A, Musalam AO. Phenotypic characterization of the infiltrating immune cells in normal prostate, benign nodular prostatic hyperplasia and prostatic adenocarcinoma. Experimental and Molecular Pathology. 2009;86(2):108-13.

26. Ammirante M, Luo J-L, Grivennikov S, Nedospasov S, Karin M. B-cell-derived lymphotoxin promotes castration-resistant prostate cancer. Nature. 2010;464(7286):302. 27. Shimabukuro-Vornhagen A, Schlößer HA, Gryschok L, Malcher J, Wennhold K, Garcia-Marquez M, et al. Characterization of tumor-associated B-cell subsets in patients with colorectal cancer. Oncotarget. 2014;5(13):4651.

28. Ansell SM, Lesokhin AM, Borrello I, Halwani A, Scott EC, Gutierrez M, et al. PD-1 blockade with nivolumab in relapsed or refractory Hodgkin's lymphoma. New England Journal of Medicine. 2015;372(4):311-9.

29. Westin JR, Chu F, Zhang M, Fayad LE, Kwak LW, Fowler N, et al. Safety and activity of PD1 blockade by pidilizumab in combination with rituximab in patients with relapsed follicular lymphoma: a single group, open-label, phase 2 trial. The Lancet Oncology. 2014;15(1):69-77.

30. Qian L, Bian G-R, Zhou Y, Wang Y, Hu J, Liu X, et al. Clinical significance of regulatory $\mathrm{B}$ cells in the peripheral blood of patients with oesophageal cancer. Central-European Journal of Immunology. 2015;40(2):263.

31. Olkhanud PB, Damdinsuren B, Bodogai M, Gress RE, Sen R, Wejksza K, et al. Tumor-evoked regulatory $\mathrm{B}$ cells promote breast cancer metastasis by converting resting CD4+ T cells to T-regulatory cells. Cancer Research. 2011;71(10):3505-15.

32. Zhou X, Su Y-X, Lao X-M, Liang Y-J, Liao G-Q. CD19+ IL-10+ regulatory B cells affect survival of tongue squamous cell carcinoma patients and induce resting CD4+ T cells to CD4+ Foxp3+ regulatory $\mathrm{T}$ cells. Oral Oncology. 2016;53:27-35 PubMed .

33. Woo JR, Liss MA, Muldong MT, Palazzi K, Strasner A, Ammirante M, et al. Tumor infiltrating B-cells are increased in prostate cancer tissue. Journal of Translational Medicine. 2014;12(1):30.

34. Maia MC, Hansen AR. A comprehensive review of immunotherapies in prostate cancer. Critical reviews in oncology/hematology. 2017;113:292-303 PubMed .

35. Pasero C, Gravis G, Guerin M, Granjeaud S, Thomassin-Piana J, Rocchi P, et al. Inherent and tumor-driven immune tolerance in the prostate microenvironment impairs natural killer cell antitumor activity. Cancer Research. 2016;76(8):2153 PubMed -65.

36. Flavell RA, Sanjabi S, Wrzesinski SH, Licona-Limón P. The polarization of immune cells in the tumour environment by TGF $\beta$. Nature Reviews Immunology. 2010;10(8):554. 
37. Miller AM, Lundberg K, Özenci V, Banham AH, Hellström M, Egevad L, et al. CD4+ CD25high T cells are enriched in the tumor and peripheral blood of prostate cancer patients. The Journal of Immunology. 2006;177(10):7398-405.

38. Sfanos KS, Bruno TC, Maris CH, Xu L, Thoburn CJ, DeMarzo AM, et al. Phenotypic analysis of prostate-in- filtrating lymphocytes reveals TH17 and Treg skewing. Clinical Cancer Research. 2008;14(11):3254-61.

39. Zhou J, Min Z, Zhang D, Wang W, Marincola F, Wang $\mathrm{X}$. Enhanced frequency and potential mechanism of $\mathrm{B}$ regulatory cells in patients with lung cancer. Journal of Translational Medicine. 2014;12(1):304.

40. Mauri C, Menon M. The expanding family of regulatory B cells. International Immunology. 2015;27(10):479-86. 